\title{
On the influence of big data on the ideological and political education in colleges and universities
}

\author{
Yandong ZHANG \\ Shandong Water Polytechnic \\ Rizhao,276826,China
}

\begin{abstract}
We need to make a new summary and explanation on the new circumstances and new issues that data development brought to University's ideological and political education, which is not only a new mission for ideological and political educators in the era, but also new opportunities for innovation and development of ideological and political education theory. From the perspective of pedagogy, sociology and other disciplines, this paper discusses and illustrates the basic elements content optimization, model building, etc. of ideological and political education in colleges and universities in the age of big data, , from an entirely new perspective.
\end{abstract}

Keywords- big data; ideological and political education; influence

\section{INTRODUCTION}

For the "big data" (Big data) research firm Gartner gives this definition. "Big Data" needs new processing mode to have a stronger decision-making power, strength and insight discovery process optimization capabilities of massive, high growth and diversified information assets.

Big Data technology strategic significance lies in not grasping the huge data, but specialized treatment to these meaningful data. In other words, if data is an industry, the key to this industry to be profitable is to upgrade the data "process capability", through the "process" to achieve data "value added."

From a technical point of view, the relationship between big data and cloud computing is as inseparable as a coin's front and back side. Big Data is bound not to use a single computer for processing, but to adopt a distributed architecture. It features lies in massive data distributed data mining, but it must rely on distributed processing , distributed database and cloud storage and virtualization technology of cloud computing,.

With the arrival of the era of cloud, big data has attracted more and more attention. "The head" of the team of analysts believe that Big data is generally used to describe a lot of unstructured data and semi-structured data created by a company, whose download to relational database for analysis costs too much time and money. Big data analytics and cloud computing are often linked together, because real-time analysis of large data sets need framework like Map Reduce to assign work to tens, hundreds or even thousands computer.

Large data requires special techniques to efficiently process large amounts of time-tolerant data. It fits big data technologies, including massively parallel processing (MPP) database, data mining grids, distributed file systems, distributed databases, cloud computing platform, the Internet and scalable storage systems.

\section{STRUCTURE OF BIG DATA}

Big Data is a representation or feature of the development of the Internet at this stage only, it is not necessary to maintain the myth of it or awe, under the background of cloud computing as the representative of technological innovation, the data which is originally difficult to collect and use starts easily be used up, big data will gradually create more value for mankind through continuous innovation industries.

Secondly, we detailed analysis it from all aspects if we want to understand big data, I started to expand from three flooders:

The first level is the theory, a theory is a necessary way of cognition, and it was widely accepted as baseline and dissemination. Here the definition of the feature of big data is to understand the industry as a whole and qualitative portrayed; Discussion on the value of big data to in-depth analysis of large data where precious; insight into the development trend of big data; from the perspective of this special and important data privacy and data to watch the long-term game between people and data.

The second level is technology, which is the cornerstone of means of data values and the way forward. Here respectively, we illustrate the major data collection, processing and storage to the formation of the entire process through distributed processing and storage technology of cloud computing and sensing technologies development

The third level is to practice, practice reflects in the ultimate value of big data. Data from the Internet here, the Government's data, large enterprise data and personal data to paint four large data showed rosy scenario and the forthcoming implementation of the blueprint.

\section{MAJOR CHARACTERISTICS OF BIG DATA}

Compared to traditional data warehousing applications for large data analysis, has a large amount of data and complex query analysis and so on. "The Computer Journal," 
published of "big data architecture: Challenges, Present and Future," the article analyzed and summarized several important characteristics of big data analytics platform need to have on the current mainstream implementation platform parallel database, Map Reduce, and the architecture based on a mix of both, pointed out their strengths and weaknesses, but also introduced all directions of research status and efforts on big data analysis and made the prospects of future research. 4 "V" of big data or those characteristics has four levels: First, the data volume is huge. From TB level, jumped to the PB level; second, the data type range widely, including web logs, videos, pictures, location information that are previously mentioned, and so on. Third, the processing speed is fast, 1 second law, you can quickly obtain high-value information from the various types of data, which is also the essentially different place compared with traditional data mining techniques. Finally, properly leveraging data and accurate analysis will bring high value return. The industry could be classified in four "V" - Volume (large data volume), Variety (data type range), Velocity (processing speed), and Value (value low density).

To some extent, the data analysis of big data is cuttingedge technology. In short, from various types of data, ability to quickly gain valuable information is a large data technology. Understand that it is vital, and that is what prompted the potential of the technologies available to many businesses.

The core data's value is in storage and analysis of massive data. Compared to other existing technology, big data's advantages' which is "cheap, fast, and optimize" is optimal in terms of cost.

\section{DATA OPPORTUNITIES}

Ever since the IT department existed, the Board has been asking experts on information management to provide insight. In fact, as early as 1951, snack cakes demand forecasting led to the birth of the first commercial applications of the computer. Since then, the ability that we use technology to identify trends and develop strategies and tactics of continually improves exponentially.

Today, business intelligence (using the data mode to see everything around curves) ranked CXO's top priority. In an ideal world, IT is enormous leverage, changed the company's influence and bring competitive differentiation, save money and increase profits, pleasure buyers, reward loyal customers, change potential customers into customers, increase the attractiveness of defeat competitors, pioneer user base and create markets.

Big Data analysis is the evolution of business intelligence. Today, sensors, GPS systems, QR codes, social networks are creating a new data stream. All of these can be excavated, which opportunities are created by the real breadth and depth of information. To make the data meaningful, so that SMEs can gain competitive advantage by means of get closer to their customers, data integration, and data management is the key.

Faced with the threat from globalization to the recession storm, IT departments need to lead the charge in large data nuggets; the winner in the new economic environment will be the best indicator to understand what affects people in their stride.

Of course, businesses will still need smart people to make wise decisions, and understand what they are facing; in the case of full use the data the ability of extra sensory perception can be given. It is clear that in the foreseeable future, privacy is still an important consideration, but ultimately technology for understanding behavior will bring a win-win situation for all aspects, let the seller know buyers, so that buyers like to buy things.

\section{FURTHER DEVELOPMENT OF FIVE MAJOR DATA FACILITATES THE DEVELOPMENT OF IDEOLOGICAL AND POLITICAL EDUCATION}

\section{A. Promotion of big data on ideological and political education}

Big data itself is a sign of progress of the times, as most of the educators of ideological and political education subject to change and update the concept and actively adapt to the context of big data models. Change the past of educatorscentered and book knowledge-centered transmission model, with instilling as the way. Big data development and changes contacts between ideological and political educators and the education, due to the large data has the characteristic of virtual reality, so that education and educators can take advantage of anonymous communications network as a carrier. This form of communication has the advantages that traditional methods cannot match, more in line with the development of the character of people. In this communication, there is a completely equal relationship between man and man, and downplayed the role of both sides, educated minds' accept and be able to better translate into action. It can also bring more first-hand material to organizations that play an educational role and individuals, promptly adjusted according to the changing situation of education methods and content, so as to enable the two sides to better play to their initiative in the whole educational activity.

\section{B. Promotion of big data on the development of a large ideological and political educated}

Ideological and political education goal is to develop "four" newcomers. Network era, accelerate the realization of this goal. Big Data ideological and political education for the role of the educated is a revolutionary. The post-figurative characteristic of big data is a good interpretation of the ideological and political education educated both ideological and political education in the object, but also the body. In the Internet age because educated acceptance of knowledge, did not have the time difference and educators, and even the advance. This greatly increased the enthusiasm, big data educated independent study carried massive knowledge, so that access to education is educated have more choices, which will also be able to better promote educated according to their own to develop their own interests, but also improve the acceptability of the ideological and political education. 


\section{Promotion of big data on content and methods of ideological and political education}

Big Data for the ideological and political education provides a new means to put forward new requirements. Because college students are high network usage groups, effected by large data gradually. If educators are able to make full use of the network to guide educates and dredge, will have a multiplier effect. Big Data has changed the unity means of education to diversified means of education. Not only that, it also changed the "man - man" model, into a "man - machine - man" mode. This model improves the educated choosing enthusiasm and acceptability, changing the original choice of ideological and political education authority submissive type and content, which is more conducive to communication between educators and the educated.

\section{BIG DATA CHALLENGES IDEOLOGICAL AND POLITICAL EDUCATION IN COLLEGES AND UNIVERSITIES}

Of course, the General data about the role of ideological and political education has two sides. We must clearly see its adverse effects at the same time actively using data for ideological and political education.

\section{A. Big data challenges educators}

Big data without center is a shock for Centre theory of traditional education. The data's Metaphor and flat features, to a large extent, make the educators lost ideological and political education subject status. This shake is not conducive for the advancement of education and educational activities. On the one hand education authorities' own consciousness is reduced, making it impossible to make better use of traditional and other effective ways to instill ideological and political education. On the other hand, educators' monopoly of information and knowledge has ceased to exist, which makes the educated have more choices, which actually increases the difficulty educators' education.

\section{B. Entertainment for Big Data educated ideological and political education significantly weakened}

As for the reason for large data quickly became educators' favorite, the entertainment is a very important factor. Big Data mixed with good and bad, in which pornography, junk culture is accounted for a considerable part. These things attract educators, far more than many mainstream cultures, which also brought a series of social problems, constitute a serious interference for ideological and political education, and with a significant negative impact on college students, whose speculation ability is poor, and worldview, philosophy, and values are not mature yet. Some people's mind eroded by pornography, thus trigger the criminal case which is often found in newspapers, thought- provoking. There are some people though no crime, but because of Internet addiction, abandoned their studies and become withdrawn and away from society, a "network invisible man." Meanwhile, due to the large data, where also exists a tendency cultural hegemony, leads to some college students' decreasing identity in favor of the existing political system and turning to blind yearning Western so-called "democracy" and "human rights", thus weaken national concepts and ideas of patriotism and seriously broken ring the effectiveness of our ideological and political education.

\section{Adverse effects of big data on methods and the environment of ideological and political education}

Ideological and political education through network activities tend to be in "virtual reality" cases, communication between educators and education are not face to face, real exchanges, but through man-machine-man mode. That might make both sides lack a true emotional communication, made it hard to play teachers' role model. Meanwhile, the freedom of cyberspace brings a major external risk when we launch Internet ideological and political education. This risk is mainly manifested in the lure of cyberspace, deception, and uncertainty.

\section{CONCLUSIONS}

With the development of social and technological progress, ideological and political education must continue to innovate in order to follow the pace of development in the community, to occupy the ideological and political education of college students' camp, to effectively guide the ideological and political education objects and to service in the overall the urgent developing need for college students. Innovation of ideological and political education in network, give full play to the advantages of data, and to disseminate rich, vivid and correct ideological and political education, and help students develop ideas to form the required age, political views, ethics and health mental state.

\section{References}

[1] Liang Yu Yan Impact Campus Media on ideological and political education of [D]. China Ocean University, 2013.

[2] Bai Yu. Influence and Countermeasures network spread to the ideological and political education [D]. Dalian University of Technology, 2005.

[3] JI Hai Ju new media era of ideological and political education research [D]. Nanjing Normal University, 2013.

[4] Huang Fafang Network Ideological and Political Education and Countermeasures [D]. Central China Normal University, 2003.

[5] Liu Yi Network on Ideological and Political Education Challenges and Strategies [D]. Southwestern University, 2010.

[6] Lin Runjing. Influence and Countermeasures of new media on the ideological and political education [D]. Soochow University, 2012. 